\title{
Nice Kids, Healthy Kids? Prosocial Behavior, Psychological Problems and Quality of Life in Children, Preadolescents, and Adolescents with and without Chronic Health Conditions
}

\author{
Carlos Carona ${ }^{1,2, *}$, Catarina Vitorino ${ }^{1}$, Ana Cláudia Alves-Nogueira ${ }^{1}$, Helena Moreira ${ }^{2}$, Maria Cristina Canavarro ${ }^{2}$, \\ Neuza Silva ${ }^{2}$ \\ ${ }^{1}$ Cerebral Palsy Association of Coimbra, Coimbra, Portugal, ${ }^{2}$ Center for Research in Neuropsychology and Cognitive-Behavioral \\ Intervention, Faculty of Psychology and Education Sciences, University of Coimbra, Portugal
}

Correspondence: ccarona@fpce.uc.pt; Tel.: +351 239 851450; Fax.: +351 239851465

Received: May 22, 2020; Accepted: July 28, 2020

\begin{abstract}
Objective - First, to compare prosocial behaviors and psychological maladjustment between children, preadolescents and adolescents with and without chronic health conditions; and second, to test the direct and indirect effects, via psychological problems, of prosocial behavior on quality of life (QoL). In addition, the invariance of this model was examined across different age groups and health conditions. Methods - Self-report questionnaires on the aforementioned variables were administered to a sample of 312 children, preadolescents and adolescents with chronic health conditions (asthma, epilepsy, and cerebral palsy) and 118 healthy controls. Univariate and multivariate analyses of covariance were conducted to examine differences in prosocial behaviors and psychological maladjustment, respectively. AMOS computational tool was used for path analysis-based mediation. Multigroup analyses were performed to test the invariance of the structural model. Results - There were no differences in the reported levels of prosocial behavior of children and youths with and without chronic health conditions. The association between prosocial behaviors and QoL was mediated by externalizing problems. The invariance of the proposed model was observed across health conditions and age groups. Conclusions - Interventions targeting prosocial behaviors may improve QoL outcomes in children and youths, through the prevention or mitigation of externalizing psychological problems, regardless of their age group or the presence/absence of a chronic health condition.
\end{abstract}

Key Words: Prosocial Behavior • Quality Of Life • Children, Preadolescents and Adolescents • Psychological Problems • Chronic Health Conditions.

\section{Introduction}

Chronic diseases are disorders that affect a person's ability to function normally (1). Over the last decades, the assessment of quality of life (QoL) in children/adolescents with chronic health conditions

*Corresponding author at: CINEICC - Center for Research in Neuropsychology and Cognitive-Behavioral Intervention, Faculty of Psychology and Education Sciences of Coimbra University, Rua do Colégio Novo - Apartado 6153, 3001-802 Coimbra, Portugal. E-mail address: ccarona@fpce.uc.pt (C. Carona). has received increasing attention. There is substantial evidence that this population is at greater risk for psychological maladjustment (2) and impaired QoL $(3,4)$, as well as at considerable risk for social maladjustment (5), when compared to their physically healthy peers. However, the focus of research has been driven from deficit-centered models to strength-based approaches, which place an emphasis on positive dimensions and resources related to the psychosocial adaptation process (5, 6). Since providing help to others is associated with 
better health and wellbeing $(7,8)$, more research is needed to examine the circumstances under which prosocial behaviors influence specific outcomes, as well as the potential mechanisms via which they may operate. Therefore, the importance of targeting prosociality and pediatric QoL is threefold: first, at the individual level, doing good for others is doing good for ourselves, improving not only wellbeing and health, but also happiness and social acceptance $(9,7)$; secondly, from an evolutionary perspective, kindness within groups confers an affiliative advantage against other groups (10); finally, a deeper understanding of these modifiable psychosocial links and variables would facilitate more comprehensive clinical formulations and increase the effectiveness of psychotherapeutic interventions for children/adolescents with chronic health conditions by clarifying the importance of targeting prosocial skills, with the ultimate intention of improving QoL outcomes.

Based on the assumptions of stress and coping theory (11), the "disability-stress-coping model" $(12,13)$ represents a theoretical framework that integrates a "risk and resistance" perspective to explain the psychosocial adjustment of children/ adolescents with chronic physical conditions. In pediatric settings, adaptation is perceived as a multidimensional construct, including the dimensions of mental health, social functioning and physical health. On a more specific level, psychological (mal)adjustment can also be considered as an indicator to ascertain the (in)adaptation of children/ adolescents (14), operationalized as the broadband dimensions of internalizing (emotional symptoms, peer problems) and externalizing problems (conduct problems and inattention/hyperactivity). Despite the fact that internalizing symptoms have been mainly related to children with chronic diseases (15), Holmbeck and colleagues (16) suggested that pediatric psychologists should direct special attention to externalizing problems, which have been hypothesized to play a distinct and important role in the adaptation of pediatric populations. Although psychological (mal)adjustment has been traditionally studied as a main adaptation outcome (e.g., 17, 14), more recent literature has suggested that it may be an important determinant of QoL (18). Given its multifaceted and holistic nature, QoL has been adopted as a major outcome measure of adaptation within the "disability-stresscoping" model (19). QoL has been defined as an overarching construct, depicting the "individual's perception of their position in life in the context of the cultural and values systems in which they live and in relation to their goals, expectations, standards and concerns" (p. 1405) (20). It comprises a wide range of areas, such as physical health, emotional wellbeing, level of independence, social relationships, personal beliefs and conditions of the environment $(20,21)$. In fact, psychiatric symptom reduction and QoL improvement are distinctive, though complementary, dimensions of treatment, with the latter comprising a more comprehensive assessment and specifically allowing the evaluation of social skills development over time (22).Prosocial behavior applies to a broad category of interactions that are beneficial to other people or, at the very least, promote harmonious relationships with others (23-26) - from the gentle, sometimes subtle behavioral forms that sooth and comfort others and lead to the development of caregiver-child attachment (e.g., a mother who softly touches the hand of her crying child) to the more sophisticated, purposeful forms of behavior committed to great social causes (e.g., a teenager who gives extensive hours of his/her life to volunteer for activities with people in need) (27).

During the past decades, science has proven that doing good to others nourishes, not only the recipient, but also the giver, in terms of his/her physical and mental health (7). In other words, a prosocial focus on caring for self and others, may be typically more beneficial than a threatening and competitive self-focus $(28,29)$. Whereas prosocial behavior refers to actions, compassion refers to the motivational background that drives those acts (30). Being compassionate involves the ability to be sensitive to suffering, triggering one's commitment to prevent or relieve it (31). Caring grows into compassion when humans' cognitive complex 
mechanisms (e.g., empathy, theory of mind, mentalizing) empower them to be motivated for caring and to understand and resonate with the minds of others (29). Psychotherapy has begun to work with compassion and prosocial cultivation as therapeutic targets themselves $(32,33)$, in order to improve positive affect and reduce stress and negative affect, as well as to enhance social interactions $(28,34)$.

According to literature, the development of these skills emerges early in life (35). With the development of abstract principles, internalized affective reactions and self-reflective sympathy and perspective taking, some of these more sophisticated modes of moral reasoning tend to increase across adolescence and seem to stabilize during early adulthood (36).

Additionally, in a more proximal level of analysis, prosocial and affiliative behaviors have been reported to be impaired in many people with psychological difficulties $(28,33)$. These social interactions are highly relevant to psychopathology assessment in childhood, because children who show excessively high or low rates of prosocial behavior may be at risk for behavioral problems and affective disorders in later life $(23,24)$. Research has demonstrated that the association between prosocial behaviors and peer relationships seems to be reciprocal, i.e., positive social behaviors promote good peer relationships and vice-versa $(9,37)$. Specifically, children who present poor social skills, disruptive, physical aggressive and antisocial behavior are thought to be at risk of experiencing peer rejection. Children with elevated Oppositional Defiant Disorder or Conduct Disorder symptoms may not have learnt prosocial skills or how to implement them $(38,39)$.

Social competence has been depicted as a potential determinant of later externalizing and internalizing problems in preadolescence, and externalizing problems in adolescence (40), as well as a salient intrapersonal factor of adaptation outcomes in the so-called "disability-stress-coping" model (13). In empirical studies, prosocial behaviors have been found to be a key predictor of social adjustment (e.g., 9) and psychological symptoms in children and adolescents $(23,24)$. However, for pediatric population with chronic illness in particular, this association has not been addressed yet. An increasing number of studies has established the importance of prosocial behaviors to the wellbeing of children (9) and adolescents (41), but the examination of an association with more comprehensive outcomes is still lacking. Since the "disability-stress-coping" model (14) defines "adaptation" as a multidimensional construct, the construct of QoL is likely to capture those outcomes in a more holistic perspective. Yet, the understanding of the mechanisms via which prosocial behaviors are likely to determine such outcomes have not been explored.

Peer relations and close friendships play a significant role in children and adolescents' emotional development, especially when it comes to adjusting to a chronic health condition (42). Data from research is not conclusive about whether these children have compromised social competence. Various studies reveal that, although many youngsters express concerns about the social impact of their disease, children with chronic health conditions (such as asthma and diabetes) do not show more social difficulties than their healthy peers $(44,45)$. In contrast, pediatric conditions that involve central nervous system dysfunction (such as cerebral palsy [CP], epilepsy, spina bifida) (46), as well as physical disabilities (47), tend to be associated with more social deficits. To meet the purpose of this research, three chronic diseases were selected because of their elevated prevalence, as well as distinctive clinical manifestations and related psychosocial challenges. Accordingly, asthma has been reported as the most common pediatric condition (48), epilepsy as one of the most prevalent neurological diseases in the developing years (49), and cerebral palsy as the most common physical disability in childhood (50). Even though asthma and epilepsy share clinical similarities (e.g., the occurrence of unpredictable episodes requiring medication intake and medical monitoring, the absence of visible physical deformities) (51), cerebral palsy has been depicted as a prototype of childhood disability (52), which 
is characterized by a distinctive outward visibility of the condition.

Given the specificities of the developmental tasks of childhood and adolescence, Wallander and Varni (12) recommended the adoption of a developmental perspective to address individual adjustment to pediatric chronic conditions. Children and adolescents face different social contexts, maturation issues and developmental tasks $(53,54)$, in which they are supposed to achieve age-related skills and abilities. In childhood, sex-segregated friendship groups are more salient, with close relations being established almost exclusively with same-sex peers (55). Adolescence is characterized by one of the greatest biological, psychological and social role changes (56); from children's concrete thinking, formal operational or abstract thinking becomes possible (57). Besides the three developmental markers in common with childhood (academic achievement, rule-governed behavior, getting along with peers), two additional areas arise in adolescence (planning the academic/professional future, experiencing romantic relationships). Nevertheless, there is a key transition period when development is progressing at such a fast pace that dramatic physical, cognitive and social changes occur - preadolescence. Across this stage, youngsters with childlike features evolve to someone with an increasing adult appearance, but with cognitive and socioemotional abilities discrepant to that observable physical growth (58). This period is marked by vital transitions: social relationships are expanding, and rational and abstract thinking abilities are flourishing (57). Data on the (in)variability of the association between prosocial behavior and QoL across these three developmental stages, while taking into account the mediation role of psychological (mal)adjustment, is definitely lacking. Additionally, preadolescence was never studied before as an independent age group, in contrast with childhood and adolescence, in the area of adaptation mechanisms and processes in pediatric psychology.

As a contribution for filling the aforementioned research gaps, the aims for this study were defined as follows: first, to assess prosocial behaviors of children/adolescents with chronic health conditions (asthma, epilepsy, cerebral palsy), in comparison to typically developing children/adolescents; and subsequently, to examine a potential pathway through which prosocial behaviors may influence QoL, by testing two dimensions of psychological maladjustment (i.e. internalizing and externalizing problems) as mediators of that relationship. The study further aimed at exploring the invariance of this model between the four health conditions (healthy, asthma, epilepsy and CP) and the three age groups (children aged 8-9, preadolescents aged 10-12, and adolescents aged 13-18 years). According to these objectives, some theoretically driven hypotheses were outlined. First, children/adolescents with chronic health condition would report decreased levels of prosocial behaviors in comparison to their healthy, able-bodied peers, particularly those with health conditions affecting the central nervous system (i.e., CP). Second, we hypothesized that higher levels of prosocial behavior would be associated with decreased levels of internalizing and externalizing problems and better QoL. Third, lower levels of internalizing and externalizing problems were hypothesized to be associated with better QoL. Although internalizing and externalizing problems were tested as mediators in the relationship between prosocial behavior and QoL, we made no specific predictions for indirect effects. Similarly, no assumptions were made for the (in) variance of the model across age-groups and health conditions.

\section{Method}

\section{Participants and Procedure}

The sample was composed of 312 pediatric patients, between 8 and 18 years old, with 3 different clinical diagnoses (asthma, $\mathrm{N}=114$; epilepsy, $\mathrm{N}=106$; and $\mathrm{CP}, \mathrm{N}=92$ ), and 118 healthy children. Children with asthma and epilepsy were recruited at the pediatric departments of three public and urban hospitals in the central region of Portugal, and children with CP were recruited at ten Portuguese Cerebral Palsy Associations (tertiary health care 
institutions) between March 2009 and September 2012. The Ethics Committee and Direction Boards of both hospitals and CP Associations approved the study. To be included in this study, children with a chronic condition had to meet the following inclusion criteria: (a) age between 8 and 18 years at the time of recruitment; (b) diagnosis of asthma, epilepsy, or CP established by a physician according to the International Classification of Diseases, Tenth Revision (ICD-10); (c) absence of comorbidity with other health conditions; and (d) ability to understand and answer the questionnaires (for children with CP, data from previous formal assessment of their intelligence quotient were collected and a value of 70 was set as the threshold). Participants completed the self-report questionnaires in a consultation office of their health institution, where a research assistant was available to assist them whenever necessary.

The community sample of healthy children was recruited in two Portuguese regular public schools between January and June 2010, considering two inclusion criteria: (1) age between 8 and 18 years at the time of recruitment; and (2) absence of a chronic health condition or developmental delay. After the Direction Boards of the schools authorized the study, a number of classes were selected to achieve the intended sample size, and questionnaires were administered to children/adolescents in the classroom. During questionnaire administration, a researcher was present to assist students in any queries regarding completion procedures.

For both groups, informed consents were obtained from all parents and adolescents older than 13 , and informal assents were obtained from children.

\section{Measures}

Children's quality of life. QoL was assessed by the Portuguese self-report version of the KIDSCREEN-10 index $(59,60)$, a 10-item questionnaire that assesses general subjective health and well-being (e.g., "Have you felt fit and well?"; "Have you had fun with your friends?") of healthy and chronically ill children between 8 and 18 years old. This measure is answered using a 5-point Likert scale that ranges from 1 ("never; not at all") to 5 ("always; extremely"), with higher scores indicating better QoL. In the present sample, the Cronbach's alphas ranged from 0.74 (epilepsy) to 0.81 (asthma).

\section{Children's Prosocial Behavior and Psycholo- gical Problems}

The Portuguese self-report version of the Strengths and Difficulties Questionnaire $(61,62)$ was used to assess prosocial behavior (e.g., "I try to be nice to other people. I care about their feelings"), internalizing (e.g., "I worry a lot") and externalizing problems (e.g., "I get very angry and often lose my temper"). The questionnaire is answered on a Likert-type response scale with three options $(0=$ "not true", 1="somewhat true", and 2="certainly true"), with higher scores indicating more psychological problems or prosocial behavior. Acceptable internal consistency values were obtained for the prosocial (from 0.64 to 0.74 , epilepsy and healthy respectively), internalizing (from 0.62 to 0.72 , epilepsy and CP groups respectively) and externalizing (from 0.67 to 0.73 , CP and healthy groups respectively) subscales.

\section{Statistical Analyses}

The statistical analyses were conducted with SPSS v.20.0 (SPSS Inc., Chicago, IL, USA). Except for socio-demographic and clinical variables, missing data, which were random and less than 5\% of the values, were replaced with the individual mean score for each variable. Descriptive statistics were calculated for socio-demographic and clinical variables and the homogeneity of children's socio-demographic characteristics between health conditions was examined with Chi-square tests for categorical variables or with univariate analyses of covariance for continuous variables. The main and interaction effects of health condition (healthy, asthma, epilepsy and CP) and age groups (children aged 8-9, pre-adolescents aged 10-12 and adoles- 
cents aged 13-18) on children's prosocial behavior and QoL were examined with univariate analyses of covariance (ANCOVA) and on internalizing and externalizing problems with a multivariate analyses of covariance (MANCOVA), controlling for gender by including it as covariate. When univariate main effects were significant, post-hoc analyses were performed, using pairwise comparisons with a Bonferroni correction [mean difference (MD), standard error (SE)], to examine which groups differed significantly. Significant interaction effects between health conditions and age groups were explored using pairwise comparisons with a Bonferroni correction, comparing the effect of the condition at each level of age category and the effect of age category for each condition.

Structural Equation Modeling (SEM) was performed with Analysis of Moment Structures (AMOS Development Corporation, Meadville, PA). The method of estimation was the maximum likelihood and the models' goodness of fit was assessed based on the chi-square statistic $\left(\chi^{2}\right)$ and on the main approximate goodness-of-fit indexes, namely the comparative fit index (CFI), the root mean square error of approximation (RMSEA) and the standardized root mean squared residual (SRMR). A model was considered to have a good fit when $\chi^{2}$ was non-significant $(P>0.05)$, CFI $\geq 0.95$, RMSEA $\leq 0.06(\mathrm{P}>0.05)$ and SRMR $\leq$ 0.08 , and an acceptable fit when $\mathrm{CFI} \geq 0.90$ and RMSEA $\leq 0.10$ (63, 64). First, the measurement model testing the hypothesized links between the latent variables and their observed indicators was examined, in order to verify the multidimensionality of theoretical constructs (latent variables) and their reliability. The construct reliability of latent variables was assessed by using composite reliability values, calculated from the squared sum of standardized factor loading divided by the addition of the squared sum of standardized factor loading and error variance terms (65). Second, we examined the structural model testing the direct effects of prosocial behavior on QoL and the indirect effects via internalizing and externalizing problems. The statistical significance of indirect effects was evalu- ated using bootstrap resampling procedures with 2000 samples (95\% bias-corrected confidence interval $[\mathrm{BC} 95 \% \mathrm{CI}])(66,67)$. Finally, multi-group analyses were performed to test the invariance of the structural model between the four health conditions (healthy, asthma, epilepsy and CP) and the three age groups (children aged 8-9, pre-adolescents aged $10-12$, and adolescents aged 13-18 years). We tested the baseline model for each group separately, and subsequently we conducted multi-group analyses using the chi-square difference method $\left(\Delta \chi^{2}\right)$ to compare the unconstrained model with a model in which measurement weights, structural weights and structural covariances were sequentially and cumulatively fixed to be equal across groups (68).

\section{Results}

\section{Sample Characteristics}

Four hundred and fifty-nine children with different health conditions (healthy, $\mathrm{N}=118$; asthma, $\mathrm{N}=118$; epilepsy, $\mathrm{N}=113$; $\mathrm{CP}, \mathrm{N}=110$ ) agreed to participate in the study. Of these, 28 cases were excluded due to the presence of comorbidities with other chronic health conditions and one case was excluded due to missing data in a ratio greater than $5 \%$ of the values. The final sample included 118 healthy children and 312 pediatric patients with asthma $(\mathrm{N}=114)$, epilepsy $(\mathrm{N}=106)$ and $\mathrm{CP}$ $(\mathrm{N}=92)$. The socio-demographic and clinical characteristics of the sample are presented in Table 1. No significant differences between groups with different health conditions were found for children's socio-demographic characteristics.

\section{Main and Interaction Effects of Health Condition and Age Group}

Table 2 presents the descriptive statistics for prosocial behavior, internalizing and externalizing problems and QoL according to health condition and age groups, as well as the condition and age main effects and interaction effects. Regarding prosocial behavior, no significant main effects of health condition, $\mathrm{F}_{(3,416)}=1.81$, $\mathrm{P}=0.15, \eta_{\mathrm{p}}^{2}=0.01$, or age group, $\mathrm{F}_{(2,416)}=2.19, \mathrm{P}=0.11$, 


\begin{tabular}{|c|c|c|c|c|c|c|}
\hline \multicolumn{2}{|c|}{ Sample characteristics } & $\begin{array}{l}\text { Healthy } \\
N=118\end{array}$ & $\begin{array}{l}\text { Asthma } \\
\mathrm{N}=114\end{array}$ & $\begin{array}{l}\text { Epilepsy } \\
\mathrm{N}=106\end{array}$ & $\begin{array}{l}\text { Cerebral palsy } \\
\mathrm{N}=92\end{array}$ & $\begin{array}{l}\text { Differences } \\
\text { between samples }\end{array}$ \\
\hline \multicolumn{7}{|c|}{ Sociodemographic characteristics } \\
\hline \multicolumn{2}{|c|}{ Age (years), M (SD) } & $12.29(2.97)$ & $12.63(2.73)$ & $11.91(2.79)$ & $12.03(2.82)$ & $\mathrm{F}=1.39 ; \mathrm{P}=0.24$ \\
\hline \multirow{4}{*}{$\begin{array}{l}\text { Age group, } \\
\text { n }(\%)\end{array}$} & Children (8-9 years) & $28(23.7 \%)$ & $16(14.0 \%)$ & $23(21.7 \%)$ & $21(22.8 \%)$ & \multirow[t]{4}{*}{$\chi^{2}=5.00 ; P=0.54$} \\
\hline & Pre-adolescents (10-12 years) & $34(28.8 \%)$ & $41(36.0 \%)$ & $37(34.9 \%)$ & $28(30.4 \%)$ & \\
\hline & Adolescents (13-18 years) & $56(47.5 \%)$ & $57(50.0 \%)$ & $46(43.4 \%)$ & $42(45.7 \%)$ & \\
\hline & Missing & - & - & - & $1(1.1 \%)$ & \\
\hline \multirow{2}{*}{$\begin{array}{l}\text { Gender, } \\
\text { n (\%) }\end{array}$} & Male & $59(50.0 \%)$ & $67(58.8 \%)$ & $54(50.9 \%)$ & $51(55.4 \%)$ & \multirow[t]{2}{*}{$\chi^{2}=2.27 ; P=0.52$} \\
\hline & Female & $59(50.0 \%)$ & $47(41.2 \%)$ & $52(49.1 \%)$ & $41(44.6 \%)$ & \\
\hline \multicolumn{2}{|c|}{ Clinical characteristics $^{\dagger}$} & & & & & - \\
\hline \multicolumn{2}{|c|}{ Age at diagnosis (years), M (SD) } & - & $4.90(4.30)$ & $7.21(3.39)$ & - & - \\
\hline \multicolumn{2}{|c|}{ Length of disease (years), M (SD) } & - & $8.21(4.25)$ & $4.81(3.68)$ & - & - \\
\hline \multirow{8}{*}{$\begin{array}{l}\text { Disease severity } \\
\text { for asthma }{ }^{\ddagger} \\
\text { epilepsy }{ }^{\$} \\
\text { CP\|, } \mathrm{N}(\%)\end{array}$} & $\begin{array}{l}\text { Intermittent/ Not at all severe/ } \\
\text { Level I }\end{array}$ & - & $65(57.0 \%)$ & $16(15.1 \%)$ & - & - \\
\hline & $\begin{array}{l}\text { Mild persistent/ A little severe/ } \\
\text { Level II }\end{array}$ & . & $26(22.8 \%)$ & $16(15.1 \%)$ & - & - \\
\hline & $\begin{array}{l}\text { Moderate persistent/ Somewhat } \\
\text { severe/ Level III }\end{array}$ & - & $10(8.8 \%)$ & $17(16.0 \%)$ & - & - \\
\hline & $\begin{array}{l}\text { Severe persistent/ Moderately severe/ } \\
\text { Level IV }\end{array}$ & - & $4(3.5 \%)$ & $13(12.3 \%)$ & - & - \\
\hline & - / Quite severe/ Level V & - & - & $2(1.9 \%)$ & - & - \\
\hline & - / Very severe/ - & - & - & $2(1.9 \%)$ & - & - \\
\hline & - / Extremely severe/ - & - & - & $0(0.0 \%)$ & - & - \\
\hline & Missing & - & $9(7.9 \%)$ & $40(37.7 \%)$ & - & - \\
\hline \multicolumn{3}{|c|}{ Use of medication, $\mathrm{N}(\%)$} & - & $91(85.8 \%)$ & $27(29.3 \%)$ & - \\
\hline
\end{tabular}

"Socio-demographic information was reported by parents; ${ }^{\dagger}$ Specific clinical information was reported by physicians for each clinical group (except for $\mathrm{CP}$ ); ${ }^{\ddagger}$ The severity of asthma was classified into 4 categories (intermittent, mild persistent, moderate persistent, and severe persistent), according to the Global Initiative for Asthma guidelines (69); § The severity of epilepsy was classified into 7 levels from "not at all severe" to "extremely severe", according to the Global Assessment of Severity of Epilepsy (GASE) Scale (70). "Levels of function in cerebral palsy were classified into 5 levels, according to the Gross Motor Function Classification System (GMFCS) - Expanded and Revised (71).

$\eta_{\mathrm{p}}^{2}=0.01$, as well as no significant interaction effects between condition and age group, $F_{(6,416)}=0.71$, $\mathrm{P}=0.64, \eta_{\mathrm{p}}^{2}=0.01$, were found.

The MANCOVA for psychological problems revealed significant multivariate differences across health conditions, Wilks' Lambda $=0.93$, $\mathrm{F}(6,830)=5.26, \mathrm{P}<0.01, \eta_{\mathrm{p}}^{2}=0.04$, and age groups, Wilks' Lambda $=0.97, \mathrm{~F}(4,830)=3.56, \mathrm{P}<0.01$, $\eta_{\mathrm{p}}^{2}=0.02$. In addition, the interaction effect of condition $\mathrm{X}$ age group on psychological problems was also significant, Wilks' Lambda $=0.94, \mathrm{~F}(12,830)=2.09$, $\mathrm{P}=0.02, \eta_{\mathrm{p}}^{2}=0.03$. The univariate effects for internalizing and externalizing problems are presented in
Table 2. The post-hoc pairwise comparisons with Bonferroni correction for internalizing problems showed that, for the group of adolescents aged 13-18 years, healthy adolescents had lower levels of internalizing problems than those with CP $[\mathrm{MD}(\mathrm{SE})=0.20$ (0.06), $\mathrm{P}<0.01]$, and that adolescents with asthma had less internalizing problems than their peers with epilepsy $[\mathrm{MD}(\mathrm{SE})=0.21(0.06), \mathrm{P}<0.01]$ or $\mathrm{CP}[\mathrm{MD}$ $(\mathrm{SE})=0.26$ (0.06), $\mathrm{P}=0.01]$. In addition, in the healthy and asthma groups, children aged 8-9 years presented more internalizing problems compared to preadolescents aged 10-12 (MD (SE) $=0.23$ (0.08), $\mathrm{P}=0.01$ for healthy; $\mathrm{MD}(\mathrm{SE})=0.24$ (0.08), $\mathrm{P}=0.02$ for asthma) 


\begin{tabular}{|c|c|c|c|c|c|c|c|c|c|c|c|c|c|c|c|}
\hline Condition & Healthy & $(\mathrm{N}=118)$ & & $\begin{array}{l}\text { Asthma } \\
\mathrm{N}=114\end{array}$ & & & $\begin{array}{l}\text { Epilepsy } \\
\mathrm{N}=106\end{array}$ & & & $\begin{array}{l}\text { Cerebral } \\
\mathrm{N}=91\end{array}$ & Palsy & & Main eff & ects & $\begin{array}{l}\text { Interaction } \\
\text { effects }\end{array}$ \\
\hline \multirow[t]{2}{*}{ Age group } & Child & $\begin{array}{l}\text { Pre- } \\
\text { adol. }\end{array}$ & Adol. & Child & $\begin{array}{l}\text { Pre- } \\
\text { adol. }\end{array}$ & Adol. & Child & $\begin{array}{l}\text { Pre- } \\
\text { adol. }\end{array}$ & Adol. & Child & $\begin{array}{l}\text { Pre- } \\
\text { adol. }\end{array}$ & Adol. & $\begin{array}{l}\text { Condi- } \\
\text { tion }\end{array}$ & Age & $\begin{array}{l}\text { Condition } \\
\text { X Age }\end{array}$ \\
\hline & $\mathrm{M}(\mathrm{SD})$ & $\mathrm{M}(\mathrm{SD})$ & $\mathrm{M}(\mathrm{SD})$ & $\mathrm{M}(\mathrm{SD})$ & $\mathrm{M}(\mathrm{SD})$ & $\mathrm{M}(\mathrm{SD})$ & $\mathrm{M}(\mathrm{SD})$ & $\mathrm{M}(\mathrm{SD})$ & $\mathrm{M}(\mathrm{SD})$ & $\mathrm{M}(\mathrm{SD})$ & $\mathrm{M}(\mathrm{SD})$ & $\mathrm{M}(\mathrm{SD})$ & $\begin{array}{l}\mathrm{F}_{(3,416)} \\
{\left[\mathrm{n}_{\mathrm{p}}{ }^{2}\right]}\end{array}$ & $\begin{array}{l}\mathrm{F}_{(2,416)} \\
{\left[\mathrm{n}_{\mathrm{p}}{ }^{2}\right]}\end{array}$ & $\mathrm{F}_{(6,416)}\left[\mathrm{n}_{\mathrm{p}}{ }^{2}\right]$ \\
\hline $\begin{array}{l}\text { Prosocial } \\
\text { behavior }\end{array}$ & $\begin{array}{l}1.73 \\
(0.33)\end{array}$ & $\begin{array}{l}1.70 \\
(0.37)\end{array}$ & $\begin{array}{l}1.68 \\
(0.33)\end{array}$ & $\begin{array}{l}1.76 \\
(0.31)\end{array}$ & $\begin{array}{l}1.65 \\
(0.36)\end{array}$ & $\begin{array}{l}1.67 \\
(0.31)\end{array}$ & $\begin{array}{l}1.64 \\
(0.36)\end{array}$ & $\begin{array}{l}1.58 \\
(0.31)\end{array}$ & $\begin{array}{l}1.66 \\
(0.39)\end{array}$ & $\begin{array}{l}1.87 \\
(0.26)\end{array}$ & $\begin{array}{l}1.69 \\
(0.35)\end{array}$ & $\begin{array}{l}1.64 \\
(0.37)\end{array}$ & $\begin{array}{l}1.81 \\
{[0.01]}\end{array}$ & $\begin{array}{l}2.19 \\
{[0.01]}\end{array}$ & $\begin{array}{l}0.71 \\
{[0.01]}\end{array}$ \\
\hline $\begin{array}{l}\text { Internalizing } \\
\text { problems }\end{array}$ & $\begin{array}{l}0.67 \\
(0.39)\end{array}$ & $\begin{array}{l}0.44 \\
(0.26)\end{array}$ & $\begin{array}{l}0.48 \\
(0.26)\end{array}$ & $\begin{array}{l}0.71 \\
(0.33)\end{array}$ & $\begin{array}{l}0.46 \\
(0.30)\end{array}$ & $\begin{array}{l}0.42 \\
(0.25)\end{array}$ & $\begin{array}{l}0.74 \\
(0.34)\end{array}$ & $\begin{array}{l}0.61 \\
(0.34)\end{array}$ & $\begin{array}{l}0.63 \\
(0.31)\end{array}$ & $\begin{array}{l}0.53 \\
(0.29)\end{array}$ & $\begin{array}{l}0.49 \\
(0.31)\end{array}$ & $\begin{array}{l}0.68 \\
(0.41)\end{array}$ & $\begin{array}{l}3.83^{\dagger} \\
{[0.03]}\end{array}$ & $\begin{array}{l}6.77^{\dagger} \\
{[0.03]}\end{array}$ & $\begin{array}{l}2.70^{\circ} \\
{[0.04]}\end{array}$ \\
\hline $\begin{array}{l}\text { Externalizing } \\
\text { problems }\end{array}$ & $\begin{array}{l}0.51 \\
(0.40)\end{array}$ & $\begin{array}{l}0.48 \\
(0.32)\end{array}$ & $\begin{array}{l}0.52 \\
(0.30)\end{array}$ & $\begin{array}{l}0.60 \\
(0.36)\end{array}$ & $\begin{array}{l}0.61 \\
(0.31)\end{array}$ & $\begin{array}{l}0.56 \\
(0.30)\end{array}$ & $\begin{array}{l}0.80 \\
(0.42)\end{array}$ & $\begin{array}{l}0.73 \\
(0.35)\end{array}$ & $\begin{array}{l}0.68 \\
(0.32)\end{array}$ & $\begin{array}{l}0.68 \\
(0.30)\end{array}$ & $\begin{array}{l}0.50 \\
(0.31)\end{array}$ & $\begin{array}{l}0.55 \\
(0.32)\end{array}$ & $\begin{array}{l}9.43^{\dagger} \\
{[0.06]}\end{array}$ & $\begin{array}{l}1.77 \\
{[0.01]}\end{array}$ & $\begin{array}{l}0.77 \\
{[0.01]}\end{array}$ \\
\hline QoL & $\begin{array}{l}4.28 \\
(0.50)\end{array}$ & $\begin{array}{l}4.31 \\
(0.48)\end{array}$ & $\begin{array}{l}3.88 \\
(0.54)\end{array}$ & $\begin{array}{l}4.28 \\
(0.63)\end{array}$ & $\begin{array}{l}4.30 \\
(0.51)\end{array}$ & $\begin{array}{l}4.01 \\
(0.58)\end{array}$ & $\begin{array}{l}3.93 \\
(0.63)\end{array}$ & $\begin{array}{l}4.12 \\
(0.52)\end{array}$ & $\begin{array}{l}4.03 \\
(0.62)\end{array}$ & $\begin{array}{l}4.10 \\
(0.56)\end{array}$ & $\begin{array}{l}4.06 \\
(0.58)\end{array}$ & $\begin{array}{l}3.95 \\
(0.59)\end{array}$ & $\begin{array}{l}2.00 \\
{[0.01]}\end{array}$ & $\begin{array}{l}7.62^{\dagger} \\
{[0.04]}\end{array}$ & $\begin{array}{l}1.52 \\
{[0.02]}\end{array}$ \\
\hline
\end{tabular}

${ }^{*} \mathrm{P} \leq 0.05 ;{ }^{\dagger} \mathrm{P} \leq 0.01$, Two-tailed.

and to adolescents aged 13-18 years $(\mathrm{MD}(\mathrm{SE})=0.19$ (0.07), $\mathrm{P}=0.02$ for healthy; $\mathrm{MD}(\mathrm{SE})=0.28(0.08)$, $\mathrm{P}<0.01$ for asthma). Regarding externalizing problems, children and adolescents with epilepsy reported higher levels of externalizing problems than those with no medical conditions $[\mathrm{MD}(\mathrm{SE})=0.24(0.05)$, $\mathrm{P}<0.01$ ], asthma [MD (SE) $=0.15(0.05), \mathrm{P}<0.01]$ or $\mathrm{CP}[\mathrm{MD}(\mathrm{SE})=0.17$ (0.05), $\mathrm{P}<0.01]$.

Finally, the two-way ANCOVA for children's QoL yielded significant main effects of age group, $\mathrm{F}_{(2,416)}=7.62, \mathrm{P}<0.01, \eta^{2}=0.04$, with adolescents aged 13-18 years presenting lower QoL than chil- dren aged 8-9 $[\mathrm{MD}(\mathrm{SE})=0.18$ (0.07), $\mathrm{P}=0.04]$ and pre-adolescents aged 10-12 $[(\mathrm{MD}(\mathrm{SE})=0.23$ (0.06), $\mathrm{P}<0.01]$.

\section{The Measurement Model}

Confirmatory factor analysis testing the links between the latent variables (prosocial behavior, internalizing and externalizing problems and QoL) and their observed indicators (Table 3) showed good factorial validity, with all observed indicators loading significantly on the respective latent

\begin{tabular}{|c|c|c|c|c|c|c|c|}
\hline \multirow{2}{*}{ Latent variable } & \multirow{2}{*}{ Observed indicator } & \multirow{2}{*}{$\begin{array}{l}\text { Tolerance } \\
\left(1-\mathrm{R}_{\mathrm{smc}}^{2}\right)\end{array}$} & \multirow{2}{*}{$\begin{array}{l}\text { Factor } \\
\text { loadings }\end{array}$} & \multirow{2}{*}{$\begin{array}{l}\text { Composite } \\
\text { reliability }\end{array}$} & \multicolumn{3}{|c|}{ Inter-correlations } \\
\hline & & & & & 1 & 2 & 3 \\
\hline \multirow[t]{5}{*}{ 1. Prosocial behavior } & SDQ item 1 & 0.66 & $0.58^{\dagger}$ & \multirow[t]{5}{*}{0.70} & \multirow[t]{5}{*}{-} & \multirow[t]{5}{*}{-} & \multirow[t]{5}{*}{-} \\
\hline & SDQ item 4 & 0.85 & $0.38^{\dagger}$ & & & & \\
\hline & SDQ item 9 & 0.51 & $0.70^{\dagger}$ & & & & \\
\hline & SDQ item 17 & 0.63 & $0.61^{\dagger}$ & & & & \\
\hline & SDQ item 20 & 0.69 & $0.55^{\dagger}$ & & & & \\
\hline \multirow[t]{2}{*}{ 2. Internalizing problems } & Emotional symptoms & 0.56 & $0.66^{\dagger}$ & \multirow[t]{2}{*}{0.63} & \multirow[t]{2}{*}{$-0.16^{*}$} & \multirow[t]{2}{*}{ - } & \multirow[t]{2}{*}{-} \\
\hline & Peer problems & 0.53 & $0.69^{\dagger}$ & & & & \\
\hline \multirow[t]{2}{*}{ 3. Externalizing problems } & Conduct problems & 0.43 & $0.76^{\dagger}$ & \multirow[t]{2}{*}{0.64} & \multirow[t]{2}{*}{$-0.49^{\dagger}$} & \multirow[t]{2}{*}{$0.61^{\dagger}$} & \multirow[t]{2}{*}{ - } \\
\hline & Hyperactivity & 0.63 & $0.61^{\dagger}$ & & & & \\
\hline \multirow[t]{2}{*}{ 4. Children's QoL } & Parcel 1 & 0.29 & $0.84^{\dagger}$ & \multirow[t]{2}{*}{0.83} & \multirow[t]{2}{*}{$0.36^{\dagger}$} & \multirow[t]{2}{*}{$-0.55^{\dagger}$} & \multirow[t]{2}{*}{$-0.58^{\dagger}$} \\
\hline & Parcel 2 & 0.30 & $0.84^{\dagger}$ & & & & \\
\hline
\end{tabular}

${ }^{*} \mathrm{P} \leq 0.05 ;{ }^{\dagger} \mathrm{P} \leq 0.01$, Two-tailed. 
variable, and, except for one observed indicator of prosocial behavior, with standardized regression weights above the threshold of 0.50 . Moreover, the squared multiple correlations $\left(\mathrm{R}_{\text {smc }}^{2}\right)$ between each observed indicator and all other observed indicators were lower than 0.90 and the tolerance values $\left(1-\mathrm{R}_{\text {smc }}^{2}\right)$ were higher than 0.10 , indicating that each observed variable explained a substantial proportion of the total standardized variance, and thus the model was not limited by multicollinearity problems (72).

The construct reliability of latent variables was good for prosocial behavior and QoL, with composite reliability values above 0.70 , and satisfactory for internalizing and externalizing problems, with composite reliability values above 0.60 . Weak to moderate correlations were found among latent variables: negative associations were found between prosocial behavior and internalizing and external- izing problems, and between both dimensions of psychological problems and QoL; and a positive association was found between prosocial behavior and children's QoL.

\section{The Mediation Model}

The structural model testing the direct and indirect effects, via internalizing and externalizing problems, of prosocial behavior on QoL had an acceptable fit, with $\chi_{(38)}^{2}=102.07, \mathrm{P}<0.01$; CFI=0.94; RMSEA $=0.06(\mathrm{P}=0.07 ; 90 \% \mathrm{CI}=0.05 / 0.08)$; and SRMR $=0.05$, and explained $42 \%$ of variability of children's QoL (Fig. 1).

Significant direct effects of prosocial behavior were found on internalizing $(\beta=-0.16, \mathrm{P}=0.03)$ and externalizing problems $(\beta=-0.49, \mathrm{P}<0.01)$ and on children's QoL $(\beta=0.17, P=0.03)$. In turn, internalizing and externalizing problems were directly

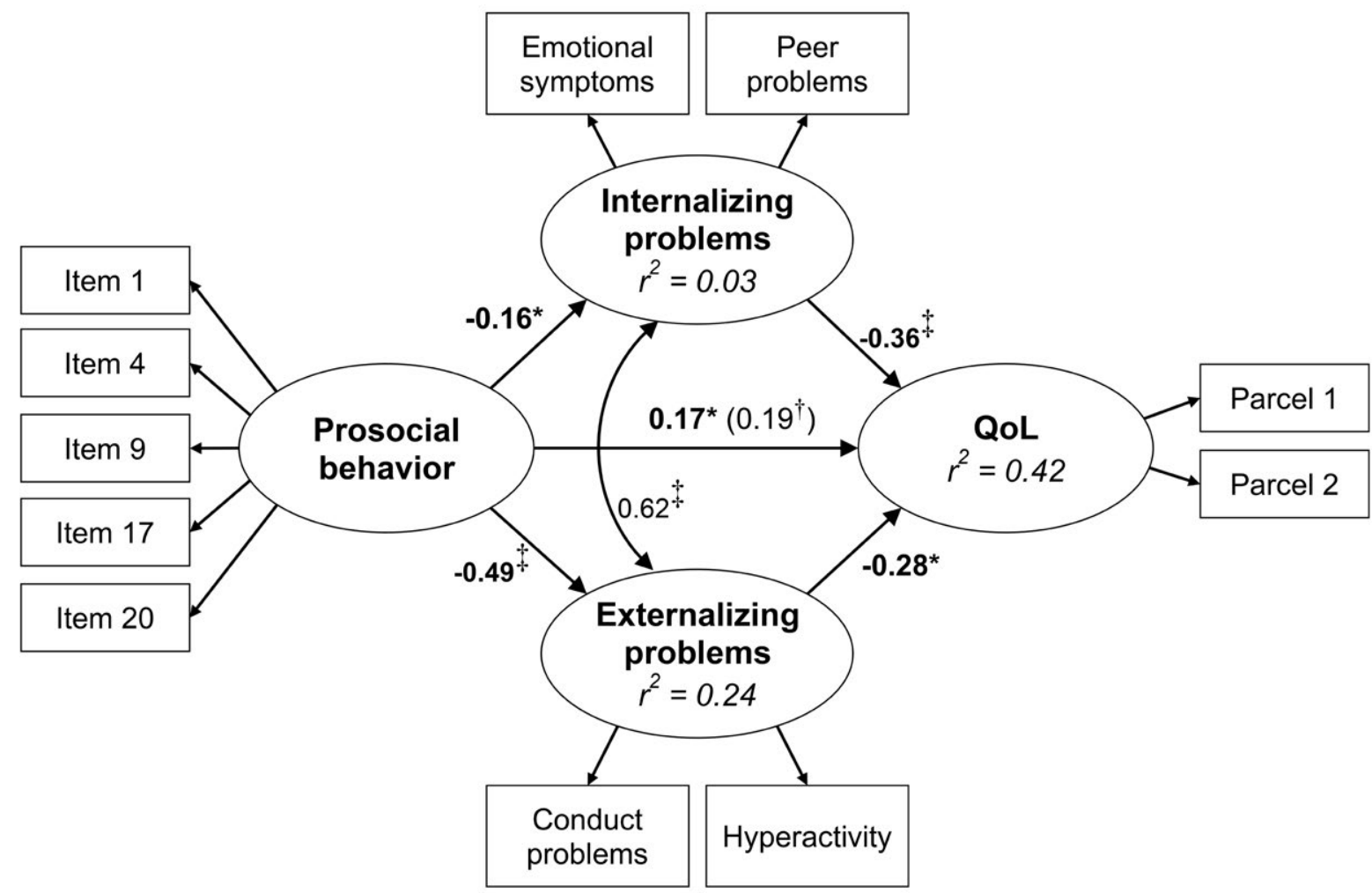

Fig. 1. Structural Equation Model Testing the Direct and Indirect Effects, Via Internalizing and Externalizing Problems, of Prosocial Behavior on Children's Quality of Life. ${ }^{*} P \leq 0.05 ;{ }^{*} P \leq 0.01 ;{ }^{*} P \leq 0.001$ two-tailed.

Note. Bold figures represent standardized regression weights for direct paths; non-bold figures in brackets represent standardized regression weights for the indirect path. For simplicity, measurement error terms are not shown. 
linked to children's QoL, with $\beta=-0.36, \mathrm{P}<0.01$ and $\beta=-0.28, P=0.02$, respectively. In addition, prosocial behavior had a significant indirect effect on children's QoL via psychological problems $(\beta=0.19$, $\mathrm{P}<0.01$, BC 95\% CI=0.06/0.35). However, when the indirect effects were examined separately for each dimension of psychological problems, only the externalizing problems emerged as a significant mediator of the association between prosocial behavior and QoL $(\beta=0.28, \mathrm{P}<0.01, \mathrm{BC} 95 \%$ $\mathrm{CI}=0.19 / 0.45)$, while the indirect effect via internalizing problems was non-significant $(\beta=0.08$, $\mathrm{P}=0.37$, BC 95\% $\mathrm{CI}=-0.08 / 0.24)$.

\section{Multi-Group Analyses}

Table 4 presents the summary of fit statistics for the mediation model tested separately for each health condition and age group, as well as the results from multi-group analyses. No significant differences were found between the unconstrained model and the nested models in which factor loadings, structural weights and structural covariances were sequentially and cumulatively fixed to be equal across groups, confirming that the parameters tested in the model were similar for both clinical and developmental groups.

\section{Discussion}

To the best of our knowledge, this is the first study to characterize the prosocial behavior of children, preadolescents and adolescents, with and without chronic health conditions. Additionally, our research had the merit of gathering evidence for a potential mechanism linking prosocial behavior with QoL outcomes in pediatric populations. These main findings add critical evidence for electing

\begin{tabular}{|c|c|c|c|c|c|c|c|c|c|}
\hline Multigroup invariance & $\chi^{2}$ & $\mathrm{df}$ & CFI & RMSEA [95\% CI] & SRMR & $\Delta \chi^{2}$ & $\Delta \mathrm{df}$ & $\mathrm{P}$ & $\triangle \mathrm{CFI}$ \\
\hline \multicolumn{10}{|l|}{ Health conditions } \\
\hline \multicolumn{10}{|l|}{ Summary of fit statistics } \\
\hline Healthy & $69.24^{\dagger}$ & 38 & 0.91 & $0.08[0.05 / .12]^{*}$ & 0.08 & - & - & - & - \\
\hline Asthma & $83.86^{\dagger}$ & 38 & 0.85 & $0.10[0.07 / .13]^{\dagger}$ & 0.08 & - & - & - & - \\
\hline Epilepsy & $53.75^{*}$ & 38 & 0.94 & $0.06[0.01 / .10]$ & 0.07 & - & - & - & - \\
\hline Cerebral palsy & 36.48 & 38 & 1.00 & $0.00[0.00 / .07]$ & 0.06 & - & - & - & - \\
\hline \multicolumn{10}{|l|}{ Multi-group analyses } \\
\hline Unconstrained model & $243.29^{\dagger}$ & 152 & 0.92 & $0.04[0.03 / .05]$ & 0.08 & - & - & - & - \\
\hline Measurement weights & $275.36^{\dagger}$ & 173 & 0.91 & $0.04[0.03 / .05]$ & 0.08 & 32.07 & 21 & 0.06 & 0.01 \\
\hline Structural weights & $292.28^{\dagger}$ & 188 & 0.91 & $0.04[0.03 / .04]$ & 0.09 & 16.92 & 15 & 0.32 & $<0.01$ \\
\hline Structural covariances & $295.20^{\dagger}$ & 191 & 0.91 & $0.04[0.03 / .04]$ & 0.09 & 2.92 & 3 & 0.40 & $<0.01$ \\
\hline \multicolumn{10}{|l|}{ Age groups } \\
\hline \multicolumn{10}{|l|}{ Summary of fit statistics } \\
\hline Children 8-9 & 41.24 & 38 & 0.99 & $0.03[.00 / .08]$ & 0.07 & - & - & - & - \\
\hline Pre-adolescents 10-12 & 51.77 & 38 & 0.96 & $0.05[.00 / .08]$ & 0.05 & - & - & - & - \\
\hline Adolescents 13-18 & $90.96^{\dagger}$ & 38 & 0.90 & $0.08[.06 / .11]^{\dagger}$ & 0.07 & - & - & - & - \\
\hline \multicolumn{10}{|l|}{ Multi-group analyses } \\
\hline Unconstrained model & $183.97^{\dagger}$ & 114 & 0.94 & $0.04[.03 / .05]$ & 0.07 & - & - & - & - \\
\hline Measurement weights & $200.11^{\dagger}$ & 128 & 0.94 & $0.04[.03 / .05]$ & 0.07 & 16.14 & 14 & 0.31 & $<0.01$ \\
\hline Structural weights & $211.64^{\dagger}$ & 138 & 0.93 & $0.04[.03 / .05]$ & 0.09 & 11.53 & 10 & 0.32 & 0.01 \\
\hline Structural covariances & $211.75^{\dagger}$ & 140 & 0.94 & $0.04[.03 / .04]$ & 0.10 & 0.11 & 2 & 0.95 & 0.01 \\
\hline
\end{tabular}

${ }^{*} \mathrm{P} \leq 0.05 ;{ }^{\dagger} \mathrm{P} \leq 0.01$. 
prosocial behavior as a strategic therapeutic target in pediatric clinical interventions, since it may improve psychological adjustment and, ultimately, QoL, regardless of the age-group and the presence/ absence of a chronic health condition.

Firstly, when compared to their healthy, typically developing peers, there were no differences in the reported levels of prosocial behavior in children/adolescents with chronic health conditions, thus infirming our first hypothesis. According to the majority of studies previously conducted on the topic of (pro)social skills and behavior, it was expected that children/adolescents with chronic health conditions would adopt less prosocial behaviors than healthy ones. This divergent result somehow challenges those prior assumptions, based on a past tendency to overestimate a deficit-centered and psychopathological perspective applied to the understanding of adaptation processes (5). Moreover, it is crucial to question and deconstruct negative expectations hold by society at large, and health professionals in particular, towards young people with a chronic condition. Despite the consensual tenet that children/adolescents with chronic health conditions face more challenges and difficulties in social interactions, particularly those with central nervous system dysfunction (such as $\mathrm{CP}$ and epilepsy) (46), the simultaneous observation of significant variability in the ways they relate to their peers (e.g., 45) has led researchers to embrace the transition to a risk-resilience framework. The focus of this comprehensive approach is on coping resources and individual competence, emphasizing that prosocial behaviors can be developed even under adverse circumstances, such as living with a chronic health condition. According to literature, prosocial skills are the product of the interplay between biologically based tendencies and socialization experiences (26), through the processes of reinforcement and modeling (30). One way of integrating the different ways through which youngsters cope with chronic conditions can be within a diathesis-stress model that proposes the interaction of individual vulnerability factors (diathesis) with the exposure to some stressful event (stress). There are at-risk individuals, those with lower levels of prosocial behaviors, that may not adjust well to their illness reporting lower QoL. On the other hand, it is possible to develop sharing, helping and cooperating skills, despite the physical condition, which can compensate this challenging context and bring better outcomes for children/adolescents' psychological adjustment. In fact, "disability-stresscoping” model $(12,13)$ conceptualizes social competence (including prosocial behaviors) within the "resistance factors", increasing the likelihood of a better adaptation to chronic illness. Socially skilled children/adolescents are characterized by a range of assertive and sociable attributes that enhance their effectiveness in social interactions. Indeed, the ability to decode others' emotions and to accurately express one's own emotional states may facilitate positive interactions and contribute to look for support when in need (37). Research has shown that prosocial behaviors have actual benefits, working as an interpersonal emotional regulator and facilitating peer acceptance and popularity $(7,9,37)$. Thus, the most straightforward insight from these results is the possibility of social competence, and specifically prosocial behaviors, standing as both a resource and a protective factor (cf. 73), although this needs to be fully ascertained in future research. This is to say that caring behaviors may not only have a positive impact for healthy, typically developing children/adolescents, but also in the context of the adversity of living with a chronic condition.

As for the second aim of this study, we found support for a mediation model in which prosocial behaviors were directly and indirectly linked to QoL outcomes of children/adolescents. First, there was a direct positive association between prosocial behaviors and QoL, highlighting that, from a holistic perspective, there are several components that can influence the wellbeing of individuals, such as prosocial skills. Following the literature review performed, developing caring behavior and compassion for others promotes abilities and confidence to cultivate supportive, affiliative interactions that enable mutually reciprocal, secure and affective relationships with others $(28,74)$. Prompting 
children/adolescents to engage in helping behaviors increases their wellbeing, emotional adjustment and social acceptance (9). Indeed, kind acts boost happiness, by increasing positive emotions and decreasing the negative ones. Love, pride and joy are some of the emotions one may feel by focusing on the needs of others, which can build deep and enduring individual personal resources and broaden cognitive and behavioral flexibility. Fredrickson (75) commented the adaptive role of positive emotions to overall wellbeing, through the enhancement of physical, psychological, intellectual and social resources, making individuals more optimistic, resilient, socially connected and healthier. As such, altruistic actions are likely to build skills for showing love and care and strengthen social bonds, thereby providing outcomes that last longer than the positive emotion itself and are useful to face adverse health conditions. This finding highlights the importance of social developmental contexts in the attainment of positive adaptation outcomes. Specifically, primary social contexts, such as the family, provide unique opportunities for social referencing, prosocial coaching, and positive emotional expressiveness, which ultimately contribute to children's adjustment and overall well-being $(23,36)$.

Moreover, the link between prosocial behavior and QoL was mediated by one of the two dimensions of psychological maladjustment, namely externalizing problems. This is to say that when a child/adolescent develops behaviors of helping others, it may positively increase QoL outcomes through the attenuation of externalizing symptoms, such as conduct problems and inattention/ hyperactivity. In fact, higher levels of prosocial behaviors are associated with good peer relationships, less rejection and more adaptive social outcomes, since these competences improve management of social challenges (9). Skillful social information processing contributes to positive peer outcomes, as well-accepted children generate higher quality solutions that are prosocial, assertive, relevant and adaptive - their social goals are characterized by the desire to maintain or enhance existing relationships and form new ones (37). These contexts of social safeness have given rise to the hedonic mentality, since the interactions relate to the provision of care, support and reassurance (74). The feelings of closeness, fondness and affection to others are the ones that can be more likely to arise. By using behaviors intended to benefit others, children/adolescents increase proximity with them and improve the quality of relationships, reducing externalizing symptoms and, consequently, enhancing their QoL. Successful regulation of the internal experience and the external display of ones' emotions contribute to positive social outcomes, by modulating behavioral expressions of feelings and urges, shifting attention toward or away from provocative stimuli and activating or inhibiting behavior (37). On the other hand, their negative outward behaviors on the external environment may be replaced by good positive behaviors (e.g., peer proximity), leading to the sense of general wellbeing. In other words, doing nice things for others contributes to the experience of positive emotions, which in turn improves social relationships and promotes greater QoL, as a result of loosening the hold that negative emotions gain on one's mind and body (75). In fact, many individuals affirm that caring for others can be a source of personal meaning and purpose in life (76).

Regarding internalizing problems, the results showed a weak association with prosocial behaviors, i.e., the development of prosocial skills may not straightforwardly contribute to prevent withdrawn, anxious and depressive behavior. This finding is in fair agreement with previous research recommendations, which stress the importance of considering both dimensions of psychological (mal)adjustment separately (16), as they exhibit different phenotypes. However, the interpretation of these data cannot be so linear, since there tend to exist a clinical overlap between internalizing and externalizing problems (e.g., 77, 78). In fact, there are externalizing symptoms that are criteria to internalizing problems (e.g., irritability, agitation for depressive disorders); in the same way, there can be externalizing problems that have internalizing difficulties underlying them (e.g., self-criticism, 
shame, elevated anxiety in conduct disorder; 84). So, even though this association is weak, prosocial behaviors can still be addressed in interventions for children/adolescents with internalizing problems (82). Although it should not be apparently the primary focus of treatment, a balance can be promoted between self-interest and concern for others $(34,80)$. Still, prosociality has been previously suggested to contribute to healthy development when appropriately regulated, but it may possibly lead to psychopathology if overly high or low $(23,24)$.

Finally, regarding the third objective, the invariance of the proposed model was ascertained across health conditions (asthma, epilepsy, CP and healthy) and age-groups (children, preadolescents and adolescents). This is to say that prosocial behaviors could be considered as a cross-contextual variable, associated with improvements in QoL via the promotion of psychological adjustment, with a clinical and developmental applicability across distinct diagnoses and different age-groups. Despite the diagnosis-related clinical specificities and agegroup developmental tasks, our findings suggest that the increase in prosocial behavior may operate through a similar mechanism and eventually lead to analogous outcomes in children, preadolescents, and adolescents with and without chronic conditions. Both groups of children/adolescents, ill and healthy, can have higher levels of QoL by (re)creating their social worlds in a balance that allows them to give a bit of their own to others. Regardless of the health condition, it is possible to achieve psychological wellbeing and satisfaction with life if a harmonious relationship with the environment is established and maintained. In support of this, Albrecht and Devlieger (81) depicted the "disability paradox", in which individuals with adverse health conditions perceived their life as good or excellent, against all odds - as illustrated again by our study, where no differences in QoL outcomes were observed between healthy and clinical groups. Considering our results, not only supportive relationships contribute to positive QoL, but also the ability to benefit others in reciprocal interactions. In fact, the balance framework proposed by the authors (81) reveals that the secondary gains from constructing and living strong and stable social relationships, with emotional give and take, seem to buffer stress and contribute to an enriched meaning of their lives. Those who have a good QoL define their social roles and remain connected, which eventually helps them making sense of their condition. Accordingly, adopting a "can do" approach to life leads to feelings of satisfaction with one's capacities and allows a proactive attitude to face adversity.

As illustrated by our results, the circumstances of suffering from a chronic health condition, though challenging and potentially stressful, do not necessarily equate to negative adaptation outcomes. This observation specifically underlines the importance of embracing a risk-resilience and strength-based approach in the research and clinical interventions with pediatric patients. Thus, adjustment to the condition is best achieved and understood through the identification and development of the patient's strengths and capabilities, rather than disabilities. Considering compassionate and prosocial behavior as powerful influences on psychological and social processes, training people to cultivate compassion motives and emotions has been a valued focus of psychotherapy (28). Moreover, our study demonstrates that this model can be applied, not only to chronic health conditions, but also to healthy youngsters. However, interventions that specifically target prosocial skills are relatively few. Apart from the classical cognitive-behavioral interventions aimed at modelling and gradually shaping prosocial behaviors (82), there is some suggestion that loving-kindness and compassion meditation are exercises that enhance unconditional, positive emotional states of kindness and compassion. While the first practice focuses awareness on loving and kind concern for all humans' wellbeing, the latter comprises alleviation of their suffering (36). Similarly, school settings may represent good opportunities to strengthen reciprocal kindness between younger populations.

\section{Limitations and Strengths}

One of the main limitations of this study is, firstly, the adoption of a cross-sectional design. Even 
though correlation research does not allow to establish causality, the study was based on a clear theoretical rationale and adopted reliable statistical procedures that allowed confidence to hypothesize directionality within the mechanisms underlying the relation between variables. In order to expand this knowledge, the link between prosocial behaviors and QoL should be addressed in future studies through longitudinal analyses. Secondly, this study may be under potential bias and generalization difficulties due to non-probabilistic sampling procedures. Nonetheless, the sample is characterized by casuistic heterogeneity (encompassing the most prevalent pediatric chronic health conditions) and it has a considerable size, which increases the power of statistical tests, allowing more accurate and reliable inferential generalizations (84). A third limitation is the exclusive reliance on selfreports, which means that some individuals with more serious cognitive impairment may have been excluded from the sample. Although the methodological recommendations state it is advisable to also include proxy-reports when addressing pediatric populations $(85,86)$, this study preferred to "hear the voices" of children/adolescents in the matters of their own functioning (87). Finally, there is the potential risk of a response style biased by social desirability, which is frequent, to some extent, in situations where people are questioned about positive social variables derived from harmful contexts they have experienced (88).

Albeit those limitations, three distinctive features are to be acknowledged as considerable strengths. First, this study has the merit of being the first to establish the link between prosocial behaviors and QoL in pediatric populations, with and without a chronic health condition. This remained an understudied topic in these populations, even though there were already some evidences of an association between prosociality and positive health outcomes in adults $(7,8)$. Secondly, this study highlighted the broad and overarching applicability of the mediation model in pediatric populations, across both age-groups and health conditions, through: (1) the inclusion of preadolescence, which has been overlooked in previous research; and (2) the analysis of the statistical invariance of the model, which has been a rare practice in psychosocial research. Finally, a third strength of this study was the integration, in the same model, of both negative (i.e. psychological maladjustment) and positive (i.e. prosocial behaviors and $\mathrm{QoL}$ ) dimensions in the assessment of adaptation process and outcomes. This allowed a multidimensional and comprehensive approach to adaptation $(89,90)$, reinforcing the statement that a satisfactory adaptation of the individual may encompass the interrelation and balance between stressful and rewarding life experiences.

\section{Future Directions}

In this study, prosocial behaviors were assessed through self-reports. The self-assessment of this kind of behaviors may result in its overestimation either because of social desirability, either because an individuals' perception or memory bias (90). Future research could then enrich a multidimensional assessment of prosocial behaviors, with other data collection methods, such as proxy-reports, interviews, or behavioral observations, in order to attain a more overarching depiction of the variable under study.

Another aspect to be addressed in future studies would be the examination of other potential mechanisms contributing to the positive impact of prosocial behaviors on QoL. Some alternative mediators may include, for example, variables related to social functioning (e.g., safeness and belonging, social support, peer acceptance), as well as to psychological functioning (e.g., self-esteem, coping, emotion regulation).

Besides, it would be valuable to expand this study to other chronic health conditions, with a visible impact due to the condition or treatment (such as dermatitis or cancer), as well as to other age-groups (e.g., preschoolers or late adolescence/ emerging adulthood). This would add substantial support for the proposed model linking prosocial behaviors and pediatric QoL, while informing prevention strategies for improving later adaptation outcomes. 
At last, some clinical interventions to improve positive social skills have shown to be effective in children/adolescents, but there is no information about the specific variables responsible for the results (83). Interventions specifically aimed at improving prosocial behaviors in pediatric populations with chronic health conditions are rare, if at all existent. In future research, in addition to testing new or adapted interventions specifically focused on increasing prosocial behavior in these populations, analyzing which formats would be more effective at what age and clinical condition (i.e. moderators), as well as which mechanisms would underlie the therapeutic change (i.e. mediators), would contribute to go beyond describing what is wrong and how to correct it, by focusing on and enhancing what is right and how to use it better.

\section{Conclusion}

Prosocial behavior is positively linked to pediatric quality of life outcomes. Youths report similar levels of prosocial behavior regardless of their health condition. Prosocial behavior may influence QoL via the attenuation of externalizing problems. Results further suggest that interventions targeting prosocial behaviors may positively affect QoL outcomes in children/adolescents, through the improvement of externalizing problems, regardless of the age group and the presence/absence of a chronic health condition. Prosociality improves adaptation outcomes across different age-groups and health conditions.

Conflict of Interest: The author declares that he has no conflict of interest.

Authors' Contributions: Conception and design: CC, NS, MCC; Acquisition, analysis and interpretation of data: CC, NS, HM; Drafting the article: CC, NS, HM, CV, AA; Revising it critically for important intellectual content: CC, MCC, NS, HM; Approved final version of the manuscript: all listed authors.

Acknowledgments: This study was supported by the Cerebral Palsy Association of Coimbra (APCC) and the Center for Research in Neuropsychology and Cognitive-Behavioral Inter- vention (CINEICC; PEst-OE/PSI/UI0730/2014) - University of Coimbra.

\section{References}

1. Ridder DD, Geenen R, Kuijer R, Middendorp HV. Psychological adjustment to chronic disease. Lancet. 2008;372:246-55.

2. Wallander JL, Varni JW, Babani L, Banis HT, Wilcox KT. Children With Chronic Physical Disorders: Maternal Reports of Their Psychological Adjustment. J Pediatr Psychol. 1988;13:197-212.

3. Immelt S. Psychological adjustment in young children with chronic medical conditions. J Pediatr Nurs. 2006;21(5):362-77.

4. Varni JW, Limbers CA, Burwinkle TM. Impaired healthrelated quality of life in children and adolescents with chronic conditions: a comparative analysis of 10 disease clusters and 33 disease categories/severities utilizing the PedsQL 4.0 Generic Core Scales. Health Qual Life Outcomes. 2007;5:43.

5. Eiser C. Psychological effects of chronic disease. J Child Psychol Psychiatry. 1990;31(1):85-98.

6. Livneh H, Lott S, Antonak R. Patterns of psychosocial adaptation to chronic illness and disability: a cluster analytic approach. Psychol, Health \& Med. 2004;9:411-430.

7. Post SG. Altruism, happiness, and health: it's good to be good. Int J Behav Med. 2005;12:66-77.

8. Poulin MJ, Holman EA. Helping hands, healthy body? Oxytocin receptor gene and prosocial behavior interact to buffer the association between stress and physical health. Horm Beh. 2013;63:510-17.

9. Layous K, Nelson SK, Oberle E, Schonert-Reichl KA, Lyubomirsky S. Kindness counts: Prompting prosocial behavior in preadolescents boosts peer acceptance and wellbeing. PloS one. 2012;7(12):e51380.

10. Wilson DS, Sober E. Multilevel selection and the return of group-level functionalism. Behav Brain Sciences. 1998;21(2):305-06.

11. Lazarus RS, Folkman S. Stress, appraisal, and coping. New York: Springer; 1984.

12. Wallander JL, Varni JW. Effects of Pediatric Chronic Physical Disorders on Child and Family Adjustment. J Child Psychol Psychiatry. 1998;39:29-46.

13. Wallander JL, Varni JW, Babani L, Banis HT, Wilcox KT. Family resources as resistance factors for psychological maladjustment in chronically ill and handicapped children. J Pediatr Psychol. 1989;14(2):157-73. 
14. Wallander JL, Varni JW, Babani L, Banis HT, DeHaan CB, Wilcox KT. Disability parameters, chronic strain, and adaptation of physically handicapped children and their mothers. J Pediatr Psychol. 1989;14:23-42.

15. Boekaerts M, Roder I. Stress, coping, and adjustment in children with a chronic disease: a review of the literature. Disabil Rehabil. 1999;21(7):311-37.

16. Holmbeck GN, Thill AW, Bachanas P, Garber J, Miller $\mathrm{KB}, \mathrm{Abad} \mathrm{M}$, et al. Evidence-based assessment in pediatric psychology: Measures of psychosocial adjustment and psychopathology. J Pediatr Psychol. 2008;33:958-80.

17. Wallander JL, Varni JW. Social support and adjustment in chronically ill and handicapped children. Amer J Comm Psychol. 1989;17:185-201.

18. Bovier PA, Chamot E, Perneger TV. Perceived Stress, Internal Resources, and Social Support as Determinants of Mental Health among Young Adults. Qual Life Res. 2004;13:161-70.

19. Koot HM. The study of quality of life: Concepts and methods. In: Koot HM, Wallander JL, editors. Quality of life in child and adolescent illness: Concepts, methods and findings. New York: Brunner-Routledge; 2001. p. 3-20.

20. The WHOQOL Group. The World Health Organization Quality of Life Assessment (WHOQOL): Position paper from the World Health Organization. Social Science \& Medicine. 1995;41:1403-09.

21. The WHOQOL Group. Development of the WHOQOL: rationale and current status. Int J Mental Health. 1994;23:24-56.

22. Bastiaansen D, Koot HM, Ferdinand RF. Psychopathology in children: Improvement of quality of life without psychiatric symptom reduction? Eur Child Adolesc Psychiatry. 2005;14:364-70.

23. Eisenberg N, Fabes RA. Prosocial development. In: Damon W, Eisenberg N, editors. Handbook of child psychology: Social, emotional, and personality development. Hoboken, NJ, US: John Wiley \& Sons Inc; 1998. p. 70178.

24. Hay DF. Prosocial development. J Child Psychol Psychiatry. 1994;35:29-71.

25. Jackson M, Tisak MS. Is prosocial behavior a good thing? Developmental changes in children's evaluations of helping, sharing, cooperating, and comforting. British J Dev Psychol. 2001;19:349-67.

26. Penner LA, Dovidio JF, Piliavin JA, Schroeder DA. Prosocial behavior: Multilevel perspectives. Annu Rev Psychol. 2005;56:365-92.
27. Padilla-Walker LM, Carlo G., editors. Prosocial development: A multidimensional approach. Oxford University Press; 2014.

28. Gilbert P. Affiliative and prosocial motives and emotions in mental health. Dialogues Clin Neuroscience. 2015;17:381.

29. Gilbert, P. The evolution and social dynamics of compassion. Social Pers Psychol Compass. 2015;9:239-54.

30. Bierhoff $\mathrm{H}$. The psychology of compassion and prosocial behavior. In: Gilbert P, editor. Compassion: Conceptualizations, research and use in psychotherapy. New York: Routledge; 2005. p. 148-67.

31. Gilbert P. Social mentalities: A biopsychosocial and evolutionary reflection on social relationships. In: Baldwin MW, editor. Interpersonal Cognition. New York: Guilford Press; 2005. p. 299-335.

32. Germer CK, Siegel RD, editors. Wisdom and compassion in psychotherapy: Deepening mindfulness in clinical practice. New York: Guilford Press; 2012.

33. Gilbert P. Compassion focused therapy: The CBT distinctive features series. London: Routledge; 2010.

34. Hoffmann S, Grossman P, Hinton D. Loving-kindness and compassion meditation: Potential for psychological intervention. Clin Psychol Rev. 2011;31:1126-32.

35. Hoffman ML. Empathy and moral development: Implications for caring and justice. New York, NY: Cambridge University Press; 2000.

36. Eisenberg N, Carlo G, Murphy B, Van Court P. Prosocial development in late adolescence: A longitudinal study. Child Dev. 1995;66:1179-97.

37. Aikins JW, Litwack SD. Prosocial skills, social competence, and popularity. In: Cillessen AHN, Schwartz D, Mayeux L, editors. Popularity in the peer system. The Guilford Press; 2011. p. 140-62.

38. Dodge KA, Pettit GS. A biopsychosocial model of the development of chronic conduct problems in adolescence. Dev Psychol. 2003;39:349-71.

39. Perren S, Stadelmann S, Von Wyl A, Von Klitzing K. Pathways of behavioral and emotional symptoms in kindergarten children: What is the role of pro-social behavior?. Eur Child Adolesc Psychiatry. 2007;16:209-14.

40. Bornstein MH, Hahn CS, Haynes OM. Social competence, externalizing, and internalizing behavioral adjustment from early childhood through early adolescence: Developmental cascades. Dev Psychopathol. 2010;22:71735. 
41. Cotney JL, Banerjee R. Adolescents' Conceptualizations of Kindness and its Links with Well-being: A Focus Group Study. J Social Pers Rel. 2019;36:599-617.

42. Varni JW, Babani L, Wallander JL, Roe TF, Frasier SD. Social Support and Self-Esteem Effects on Psychological Adjustment in Children and Adolescents with InsulinDependent Diabetes Mellitus. Child Fam Behav Ther. 1989;11:1-17.

43. Reiter-Putrill J, Waller JM, Noll RB. Empirical and theoretical perspectives on the peer relationships of children with chronic conditions. In: Roberts MC, Steele RG, editors. Handbook of pediatric psychology. 4th ed. New York, NY: Guilford Press; 2009. p. 672-88.

44. Martinez W, Carter JS, Legato LJ. Social competence in children with chronic illness: A meta-analytic review. J Pediatr Psychol. 2011;36:878-90.

45. Spirito A, Delawyer DD, Stark LJ. Peer relations and social adjustment of chronically ill children and adolescents. Clin Psychol Rev. 1991;11:539-64.

46. La Greca AM, Bearman KJ Moore H. Peer Relations of Youth with Pediatric Conditions and Health Risks: Promoting Social Support and Healthy Lifestyles. J Dev Behav Pediatr. 2002;23:271-80.

47. Stevens SE, Steele CA, Jutai, JW, Kalnins, IV, Bortolussi, JA, Biggar WD. Adolescents with physical disabilities: Some psychosocial aspects of health. J Adolesc Health. 1996;19:157-64.

48. Malveaux FJ. The State of Childhood Asthma: Introduction. Pediatrics. 2009;123(3):S129-S30.

49. Ronen GM, Streiner DL, Rosenbaum P. Health-related quality of life in childhood epilepsy: moving beyond seizure control with minimal adverse effects. Health Qual Life Outcomes. 2003;1:36-46.

50. Moreno-De-Luca A, Ledbetter DH, Martin CL. Genetic insights into the causes and classification of the cerebral palsies. Lancet Neurol. 2012;11(3):283-92.

51. Austin J, Smith M, Risinger M, McNelis A. Childhood epilepsy and asthma: comparison of quality of life. Epilepsia. 1994;35(3):608-15.

52. Raina P, O’Donnell M, Schwellnus H, Rosenbaum P, King G, Brehaut J, et al. (2004). Caregiving process and caregiver burden: conceptual models to guide research and practice. BMC Pediatr. 2004;4:1.

53. Bloomquist ML. Skills training for children with behavior problems: A parent and practitioner guidebook. New York: Guilford; 2006.

54. Carona C, Crespo C, Silva N, Lopes AF, Canavarro MC, Bullinger M. Examining a developmental approach to health-related quality of life assesment: Psychometric analysis of DISABKIDS generic module in a Portuguese sample. Vulnerable Child Youth Stud. 2013;8(3):243-57.

55. Parker JG, Rubin KH, Erath SA, Wojslawowicz JC, Buskirk AA. Peer relationships, child development, and adjustment: a developmental psychopathology perspective. In: Cicchetti D, Cohen DJ, editors. Developmental psychopathology: Theory and method. Hoboken: Wiley; 2006. p. 419-93.

56. Holmbeck GN. A developmental perspective on adolescent health and illness: An introduction to the special issue. J Pediatr Psychol. 2002;27:409-16.

57. Perry CL. Preadolescent and adolescent influences on health. In: Smedley BD, Syme SD, editors. Promoting health: Intervention strategies from social and behavioral research. Washington, DC: The National Academies Press; 2000. p. 217-53.

58. Blum RW, Astone NM, Decker MR, Mouli VC. A conceptual framework for early adolescence: a platform for research. Int J Adolesc Med Health. 2014;26:321-31.

59. Matos MG, Gaspar T, Simóes C. Health-related quality of life in Portuguese children and adolescents. Psicologia: Reflexão e Crítica. 2010;25:230-37.

60. Ravens-Sieberer U, Erhart M, Rajmil L, Herdman M, Auquier P, Bruil J, et al. Reliability, construct and criterion validity of the KIDSCREEN-10 score: a short measure for children and adolescents' well-being and health-related quality of life. Qual Life Res. 2010;19(10):1487-500.

61. Goodman A, Goodman R. Strengths and difficulties questionnaire as a dimensional measure of child mental health. J Amer Acad Child Adolesc Psychiatry. 2009;48(4):400-3.

62. Goodman A, Lamping DL, Ploubidis GB. When to use broader internalising and externalising subscales instead of the hypothesised five subscales on the Strengths and Difficulties Questionnaire (SDQ): data from British parents, teachers and children. J Ab Child Psychol. 2010;38(8):1179-91.

63. Browne M, Cudeck R. Alternative ways of assessing model fit. In: Bollen K, Long J, editors. Testing structural equation models. Newbury Park, CA: Sage Publications; 1993. p. $136-2$.

64. Hu L, Bentler P. Cutoff criteria for fit indexes in covariance structure analysis: Conventional criteria versus new alternatives. Stru Eq Model: Multidisc J. 1999;6:1-55.

65. Hair J, Black W, Babin B, Anderson R. Multivariate data analysis. 7th ed. New Jersey: Prentice Hall; 2010.

66. Preacher K, Hayes A. Asymptotic and resampling strategies for assessing and comparing indirect effects in multiple mediator models. Behav Res Methods. 2008;40:87991. 
67. Williams J, MacKinnon D. Resampling and distribution of the product methods for testing indirect effects in complex models. Stru Eq Model: Multidisc J. 2008;15:23-51.

68. Little $T$, editor. The Oxford handbook of quantitative methods in psychology (Vol. 1). New York: Oxford University Press; 2013.

69. Global Initiative for Asthma [GINA]. Global strategy for asthma management and prevention [updated 2017; cited Dec 2019]. Available from http://www.ginasthma.org.

70. Speechley KN, Sang X, Levin S, Zou GY, Eliasziw M, Smith ML, et al. Assessing severity of epilepsy in children: Preliminary evidence of validity and reliability of a singleitem scale. Epilepsy Behav. 2008;13(2):337-42.

71. Palisano R, Rosenbaum P, Bartlett D, Livingston M. Gross motor function classification system - expanded and revised. Dev Med Child Neurol. 2007;39(4):214-23.

72. Kline RB. Principles and practice of structural equation modeling. 2nd ed. New York: The Guilford Press; 2005.

73. Holmbeck G. Toward terminological, conceptual, and statistical clarity in the study of mediators and moderators: Examples from the child-clinical and pediatric psychology literatures. J Consult Clin Psychol. 1997;65:599-610.

74. Gilbert P, Basran J. The evolution of prosocial and antisocial competitive behavior and the emergence of prosocial and antisocial leadership styles. Front Psychol. 2019;10.

75. Fredrickson BL. The value of positive emotions: The emerging science of positive psychology is coming to understand why it's good to feel good. Amer Scient. 2003;91(4):330-35.

76. Gilbert P. Defense, safe(ty) and biosocial goals in relation to the agonic and hedonic social modes. World Futures. 1992;35:31-70.

77. Gilliom M, Shaw DS. Codevelopment of externalizing and internalizing problems in early childhood. Dev Psychopathol. 2004;16:313-33.

78. Wiggins JL, Mitchell C, Hyde LW, Monk CS. Identifying early pathways of risk and resilience: The codevelopment of internalizing and externalizing symptoms and the role of harsh parenting. Dev Psychopathol. 2015;27:1295-312.
79. American Psychiatric Association. Diagnostic and statistical manual of mental disorders. 5th ed. Washington, DC: Author; 2013.

80. Neff KD, Pommier E. The relationship between self-compassion and other-focused concern among college undergraduates, community adults, and practicing meditators. Self Ident. 2013;12:160-76.

81. Albrecht GL, Devlieger PJ. The disability paradox: high quality of life against all odds. Social Science \& Medicine. 1999;48(8):977-88.

82. Jongsma AE, Peterson LM, McInnis WP, Bruce TJ. The child psychotherapy treatment planner. New Jersey: Wiley; 2014.

83. Bandy T, Moore KA. What works for promoting and enhancing positive social skills: Lessons from experimental evaluations of programs and interventions. Child Trends: Fact Sheet. 2011.

84. Stevens JP. Applied multivariate statistics for the social sciences. 4th ed. Lawrence Erlbaum Associates Publishers; 2002.

85. Wallander JL, Schmitt M, Koot HM. Quality of life measurement in children and adolescents: issues, instruments, and applications. J Clin Psychol. 2001;57:571-85.

86. Wallander JL, Koot HM. Quality of life in children: A critical examination of concepts, approaches, issues, and future directions. Clin Psychol Rev. 2016;(45):131-43.

87. Varni JW, Burwinkle TM, Sherman SA, Hanna K, Berrin SJ, Malcarne VL, et al. Health-related quality of life of children and adolescents with cerebral palsy: hearing the voices of the children. Dev Medicine Child Neurol. 2005;47:592-97.

88. Tomich PL, Helgeson VS. Is finding something good in the bad always good? Benefit finding among women with breast cancer. Health Psychol. 2004;23:16-23.

89. Barlow JH, Ellard DR. The psychosocial well-being of children with chronic disease, their parents and siblings: an overview of the research evidence base. Child Care Health Dev. 2006;32:19-31.

90. Cummings EM, Davies PT, Campbell SB. Developmental psychopathology and family process: Theory, research and clinical implications. New York: The Guilford Press; 2000. 